\title{
Effect of corrosion on the quality of repair of the aluminum alloy A5083 H11 by bonded composites
}

\author{
Kaddour Sadek, Benaoumeur Aour \\ $L A B A B$ Laboratory, Department of Mechanical Engineering, \\ National Polytechnic School - Maurice Audin, Oran, 31000, Algeria \\ sadekkeaddoun@gmail.com,benaoumeur.aoun@enp-oran.dz
}

Mohammed Salah Bennouna

University of Kasdi Merbah Ouargla, Department of Mechanical Engineering, Algeria

bennouna_ms@yahoo.fr

\author{
Abderrahim Talha \\ Lille Mechanics Unit, University of Lille, (UML, EA 7512), University of Lille, 59655 Villeneuve d'Ascq, France \\ abderrahim.talba@yncrea.fr
}

\author{
Belabbes Bachir Bouiadjra, Mourad Fari Bouanani \\ LMPM Laboratory, Department of Mechanical Engineering, University Of Sidi Bel Abbes 22000, Algeria \\ bacbirbou@yahoo.fr,bouananimorad@gmail.com
}

\begin{abstract}
In this paper, the simultaneous effect of corrosion and cracking on the performance of the bonded composite patch repair in aluminum alloy A5083 marine structure was investigated using three-dimensional finite element methods. To this end, two patches made of carbon/epoxy and boron/epoxy, bonded on corroded plates with and without crack, were tested under different applied loads. The effect of both corroded and cracked materials on the damage of the adhesive FM73 was also highlighted. The obtained results show that the corrosion has a significant effect on the quality of the repair performance. Indeed, it is proved that, the rate of damage increases with the increase of the applied load and is more significant in the case of plates cracked and repaired by carbon/epoxy patch compared to that of boron/epoxy patches.
\end{abstract}

KEYwORDs. Corrosion; Damage zone; Composite patch; Aluminum alloy; Adhesive; Crack.

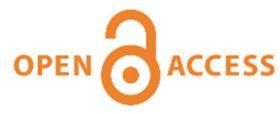

Citation: Sadek, K., Aour, B., Bennouna, M. S., Talha, A., Bachir Bouiadjra, B., Fari Bouanani, M., Effect of corrosion on the quality of repair of the aluminum alloy A5083 H11 by bonded composites, Frattura ed Integrità Strutturale, 53 (2020) 51-65.

Received: 13.12 .2019

Accepted: 07.05.2020

Published: 01.07.2020

Copyright: (C) 2020 This is an open access article under the terms of the CC-BY 4.0, which permits unrestricted use, distribution, and reproduction in any medium, provided the original author and source are credited. 


\section{INTRODUCTION}

7 he 5000 family aluminum alloys, and, especially the A5083 alloys, are known for their high resistance to corrosion salinity and ideal alloy for their weldability, making their use a better choice in the marine shipbuilding industry and offshore structures [1]. The elements $\mathrm{Mg}, \mathrm{Zn}$ or $\mathrm{Cu}$ alloyed with aluminum consolidate and reinforce the matrix. The aluminum has an excellent strength-to-weight ratio, which makes it an ideal material when specifications require high strength and minimum weight. This alloy composition makes it enable to be used for the construction of ships and boats [2].

Otherwise, the corrosion process in the marine environment is favored by the presence of a lower rte of oxygen and higher salinity, also the presence of manufacturing defect at the microscopic scale, under repeated cyclic loadings and the salinity of the water, cause the fatigue of the material which is called fatigue corrosion under stress. Most of the structural fractures in service are about $90 \%$ due to this corrosion cracking phenomena. Three main stages of a material failure have been observed: (i) initiation of the crack, (ii) propagation of the crack, and (iii) finally sudden rupture [3-5]. To remedy this kind of phenomenon and the crack propagation by corrosion, a new technique has been applied for several years based on a composite bonded to the damaged part. This technology has proven to be effective in aerospace and marine applications [6].

More recently, this technique of repairing cracked structures has been considered particularly effective in aeronautics and follows rigorous control procedures, the composite patch is applied in situ on the damaged part. Several parameters affect the integrity of composite patch repair. Among these parameters, (i) the geometric shape, the thickness, the length and the nature of the patch, (ii) the medium, (iii) the type and thickness of the adhesive, etc. [7].

In a previous work, Sadek et al. [8] analyzed by finite element, the performance of repair with patch composite using different shapes in the case of marine structures. The evolution of the damaged zone under the crack effect only has been also studied [9]. However, rare are the studies on the performance of bonded composite patch repair in corroded aluminum structures [10]. In this paper, the effect of corrosion on the quality of repair of the aluminum alloy $5083 \mathrm{H} 11$ by bonded composite is analyzed using a three-dimensional finite element method. A comparison between the obtained results using two types of patches has been presented and discussed.

\section{BACKGROUND FORMULATION}

\section{Jintegral}

he SIF calculation tool is currently chosen for computing the three-dimensional virtual crack closure technique (3DVCCT) of the asymptotic value [11]. The proposed Irwin VCCT is based on the energy balance. From this equation, stress intensity factors are given for the three fracture modes

$$
G_{i}=\frac{K_{i}^{2}}{E}
$$

where $G_{i}$ is the energy release rate for mode i, $K_{i}$ the stress intensity factor for mode i, E the elastic modulus.

The idea presented by Rybicki and Kanninen [12], is based on the calculation of the energy release rate, using Irwin assumption that the energy released in the process of crack expansion is equal to work required to close the crack to its original state, as the crack extends by a small amount $\Delta$ a. Irwin computed this work as:

$$
W=\int_{0}^{\Delta a} u(r) \cdot \sigma \cdot(\Delta a-r) d r
$$

where $u$ is the relative displacement, $\sigma$ is the stress, $r$ is the distance from the crack tip, and $\Delta a$ is the change in virtual crack length. Therefore, the energy release rate is given by:

$$
G=\lim _{\Delta a \rightarrow 0} \frac{W}{\Delta a}=\lim _{\Delta a \rightarrow 0} \frac{1}{2 . \Delta a} \int_{0}^{\Delta a} u(r) \cdot \sigma \cdot(r-\Delta a) d r
$$


The work W can be expressed as:

$$
W=\frac{1}{2} F \cdot u
$$

where $F$ is the force needed to close the crack virtually, $u$ is the crack opening displacement.

Eq (3) allows the calculation of the energy release rate for 2D FE models (modes I and II). The application of the VCCT in $3 \mathrm{D}$ FE models is commonly called the 3D VCCT. The extension of the method from 2D to 3D requires replacing Eq. (3) by the following expression:

$$
G=\frac{1}{2 h \Delta a} \int_{0}^{b} \int_{0}^{\Delta a} u(r, s) \cdot \sigma(r-\Delta a, s) \cdot d s \cdot d r
$$

where $\mathrm{s}$ is the distance from the crack tip in the third direction, and $\mathrm{h}$ is the element size in the third direction.

To apply Eq. (5) to FE models comprising 8-node brick elements, the integrals in (5) are replaced with the sum as follows:

$$
G=\frac{1}{2 h \Delta a} \sum_{k=1}^{2} F_{k i} \cdot u_{k i}
$$

where index $i$ controls direction, and index $\mathrm{k}$ controls the node $\mathrm{b}$ number.

The shear stresses in the adhesive are given by the following relationship:

$$
\tau=\frac{G_{a}}{e_{a}}\left(u_{1}-u_{2}\right)
$$

Where $u_{1}$ and $u_{2}$ are displacements in layers 1 and 2 (the plate and the patch) respectively.

Experimental design was used for the determination of the optimum patch dimensions [13-15]. Indeed, the patch dimensions process is described by a quadratic model as follows:

$$
y=a_{0}+a_{1} x_{1}+a_{2} x_{2}+a_{11} x_{1}^{2}+a_{22} x_{1}^{2}+a_{12} x_{1} x_{2}
$$

where $\mathrm{y}$ is the response of the process (i.e., the $J$ integral at the crack front in the plate) and, $x_{i}$ is the normalized centered value for each factor $u_{i}$ :

$$
\begin{aligned}
& x_{i}=\frac{u_{i}-u_{i c}}{\Delta u_{i}}=u_{i}^{*} \\
& u_{i c}=\frac{u_{\text {imax }}+u_{\text {imin }}}{2} \\
& \Delta u_{i}=\frac{\left(u_{i \max }-u_{\text {imin }}\right)}{2}
\end{aligned}
$$

The quadratic model of $J$ integral is expressed as following [16]:

$$
J=a_{0}+a_{1} L^{*}+a_{2} W^{*}+a_{3} t^{*}+a_{12} L^{*} W^{*}+a_{13} L^{*} t^{*}+a 23 W^{*} t^{*}+a_{11} L^{* 2}+a_{22} W^{* 2}+a_{33} t^{* 2}
$$

where $L^{*}$ is the length, $W^{*}$ is the width, and $t^{*}$ is the thickness of the patch. 


\section{Damage zone theory}

The joint adhesive used in this study is made of a ductile material, that has been toughened and, which is supposed to be exposed to a yielding failure. Therefore, in this case of failure study and for characterizing the damage zone, we will apply the equivalent strain of von Mises criterion given by the following expression [17]:

$$
\varepsilon_{e q}=\frac{1}{\sqrt{2}(1+v)} \times \sqrt{\left(\varepsilon_{p 1}-\varepsilon_{p 2}\right)^{2}+\left(\varepsilon_{p 2}-\varepsilon_{p 3}\right)^{2}+\left(\varepsilon_{p 3}-\varepsilon_{p 1}\right)^{2}}
$$

where $\varepsilon_{e q}$ is the equivalent strain, $\varepsilon_{p i}$ are the plastic strains in the different directions and $v$ is the Poisson's ratio.

The von Mises equivalent strain criterion is satisfied for the ultimate principal strain value of the material. The damage zone size at failure is determined when the ultimate strain of each failure criterion is defined. We use either the strain or the stress criterion to define the damage zone, but when the adhesive undergoes a significant nonlinearity the application of the strain criterion will be more appropriate [18].

It should be noted that there are two modes of failure associated with adhesive joints: (i) interfacial and (ii) cohesive failure. In the first mode, the failure load of the adhesive joint depends on the interfacial stress near the interfaces between the adhesive and the adherent [18]. The second mode will happen when cohesive failure occurs in the adhesive joint. Since cohesive failures certainly occurred in the adhesive joint, we recommend using the adhesive failure criterion for the damage zone. The failure criterion, for isotropic materials, such as the von Mises and Tresca criteria, can be used to model the adhesive failures [19]. In order to define and quantify the rate of damage, the following damage zone ratio formula can be used:

$$
D_{r}=\frac{\sum A_{i}}{L \cdot W_{a}}
$$

where $D_{r}$ is the damage zone ratio, $A_{i}$ the area over which the equivalent strain exceeds $7.87 \%$ [17], $\mathrm{L}$ the adhesive length and $W_{a}$ is the adhesive width.

\section{NUMERICAL MODELING}

7 he corroded and cracked structure is shown in Fig. 1. To study the effect of corrosion on the quality of repairs, two types of patches have been numerically tested. The first one is made of boron/epoxy and the second one of carbon/epoxy. Both are glued on two corroded aluminum plates A5083 with and without crack. The adhesive is of type FM73 with a thickness $\mathrm{e}_{\mathrm{a}}=0.15 \mathrm{~mm}$ (longitudinal Young modulus $\mathrm{E}=4.2 \mathrm{GPa}$ and longitudinal Poisson ratio $\nu=0.32$ ). Different uniform uniaxial loadings $\sigma=220,250,300$ and $350 \mathrm{MPa}$ were applied to the structure (Fig. 1). The damage ratio $D_{r}$ of the adhesive has been evaluated. The mechanical properties of both patches are selected according to several references $[9,19,20]$ and are given in Tab. 1 . The aluminum alloy plate $5083 \mathrm{H} 11$ has dimensions $254 \times 254 \times 5$ $\mathrm{mm}^{3}$ (Fig. 1) $\mathrm{H}=254 \mathrm{~mm}, \mathrm{~W}=254 \mathrm{~mm}$ and $\mathrm{e}_{\mathrm{p}}=5 \mathrm{~mm}$, with a crack length $\mathrm{a}=1.5 \mathrm{~mm}$. The mechanical properties of the plate are as follows: Young's modulus E $=69 \mathrm{GPa}$, Poisson's ratio $\nu=0.35$, the yield stress $\sigma_{\mathrm{y}}=243 \mathrm{MPa}$, the ultimate stress $\sigma_{\mathrm{u}}=347 \mathrm{MPa}$ and the elongation $\xi_{\mathrm{el}}=21.85 \%$. The composite patch has the following dimensions: $130 \times 75 \times 1.5$. The plies in the patch had unidirectional lay-up where the fibers were oriented along the specimen length direction (parallel to the load direction). Both patches are bonded on the damaged structure by $0.15 \mathrm{~mm}$ thick film of adhesive epoxy. The geometric shape of the corroded area was taken in 3D randomly with a thickness of $0.5 \mathrm{~mm}$. Noting that, the effect of the variation in thickness of the corroded area is under an advanced investigation and will be published later.

The physical interactions at aluminium/adhesive and composite/adhesive interfaces during loading are taken into account through bonded surface-to-surface contact features of Abaqus. A surface-to-surface contact definition can be used as an alternative to general contact to model contact interactions between specific surfaces in a model. In this work, at the interfaces, each mesh node is common between the adjacent structures to ensure continuity of strains and stresses. Noting that the adhesive is homogeneous elastic and isotropic, the deformation of the adhesive is under the effect of shearing and peeling. The boundary conditions used in this analysis are as follows: one end of the plate was fully fixed while the other end was subjected to a tensile stress in an increasing way using the option "STEP" general static of ABAQUS code [21]. A 
maximum increment value up to 10000 was used for the automatic increment. The minimum and maximum increment sizes are $10^{-5}$ and 1 respectively.

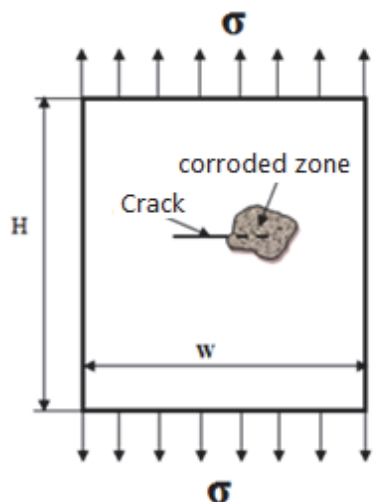

Figure 1: Geometrical model.

\begin{tabular}{lcc}
\hline Elastic properties & Boron/epoxy & Carbon/epoxy \\
Longitudinal Young modulus E1 (GPa) & 200 & 134 \\
Transversal Young modulus E2 (GPa) & 19.6 & 10.3 \\
Transversal Young modulus E3 (GPa) & 19.6 & 10.3 \\
Longitudinal Poisson ratio v12 & 0.3 & 0.33 \\
Transversal Poisson ratio v13 & 0.28 & 0.33 \\
Transversal Poisson ratio v23 & 0.28 & 0.33 \\
Longitudinal Shear modulus $G 12(\mathrm{GPa})$ & 7.2 & 5.5 \\
Transversal Shear modulus $G 13(\mathrm{GPa})$ & 5.5 & 5.5 \\
Transversal Shear modulus $G 23(\mathrm{GPa})$ & 5.5 & 3.2 \\
\hline
\end{tabular}

Table 1: Elastic properties of both patches [9,19,20].

The finite element model (Fig. 2) is composed of different substructures to model the cracked and corroded plate, the adhesive and the composite patch. The plate has four layers of elements in the direction of thickness, the adhesive has a single layer in the thickness and the patch has four layers of elements in the thickness. The commercial finite elements code ABAQUS was used for computations. The number of elements is 54517 with 77551 nodes. The element type used is C3D8R: an 8-node linear brick, reduced integration, hourglass control. The second generated model is a plate with corrosion and crack using three subsections models (plate-patch-adhesive). The number of elements is 92928 with 411791 nodes. The element type used is C3D20RH: a 20-node quadratic brick, hybrid, linear pressure, reduced integration.

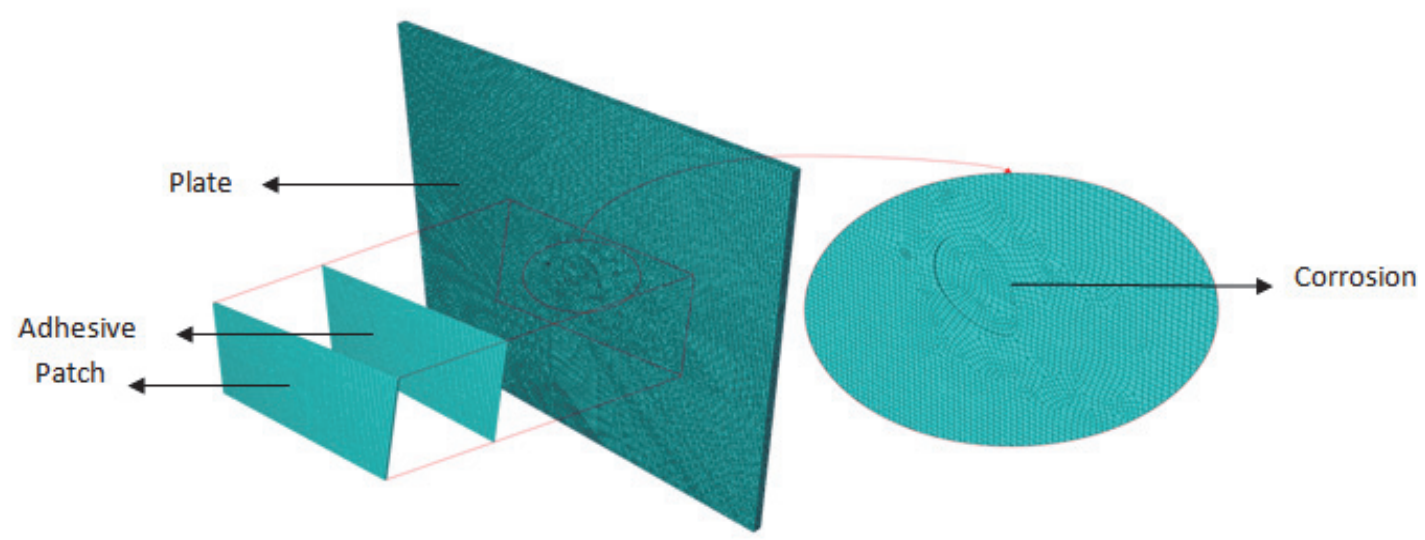

Figure 2: Finite element meshed parts of the studied model. 


\section{VALIDATION OF THE MODEL}

o validate the numerical model developed in this work, an elastic aluminium plate with and without composite patches under uniform uniaxial load with a centre crack was analysed. In order to make a comparison, the same dimensions and material properties as those used by Ayatollahi and Hashemi [22] were considered. Noting that for a central crack subjected to opening mode, the relationship between the stress intensity factor (SIF) and the far applied load $(\sigma)$ is given by: $K_{I}=Y \sigma \sqrt{\pi a}$, where $\mathrm{Y}$ is a geometric factor, depends on the plate geometry and the crack shape. Y $=1.12$ (for a finished plate containing a central crack "2a") [23].

The obtained results of the SIF were compared firstly with that of analytical solution (in the case without patch) (Fig. 2.a) and then with that of Ayatollahi and Hashemi [22] in the case with patches made in carbon/epoxy and boron/epoxy (Fig. 2.b). It can be seen that good agreement was found between the results of the present model and that of analytical and numerical results as shown in Figs. 2.a and 2.b respectively. Indeed, the maximum relative error is $4 \%$ for the case without patch, $1.96 \%$ for the case with a patch in boron/epoxy and $1.48 \%$ for the case with a patch in carbon/epoxy. Furthermore, it should be noted that the best repair performance under these conditions is obtained by using boron/epoxy patch compared to carbon/epoxy patch.

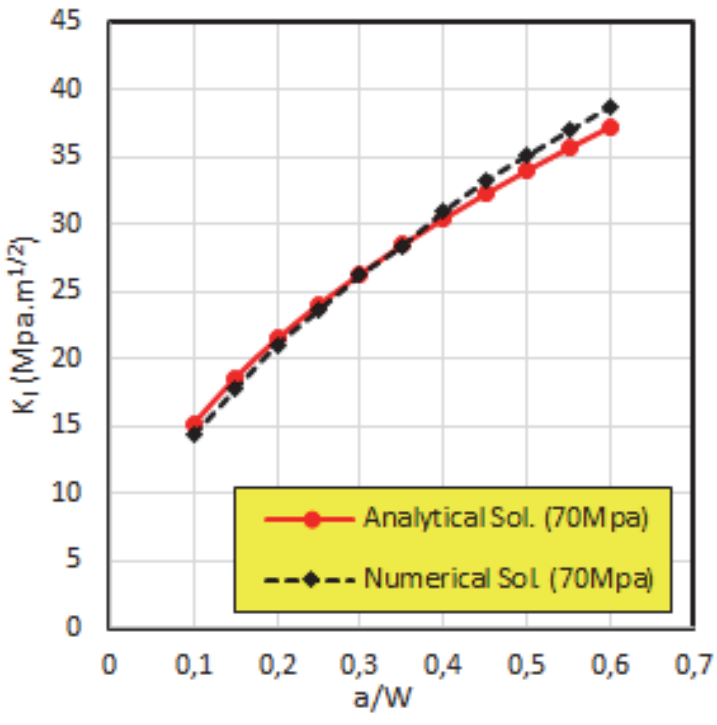

(a)

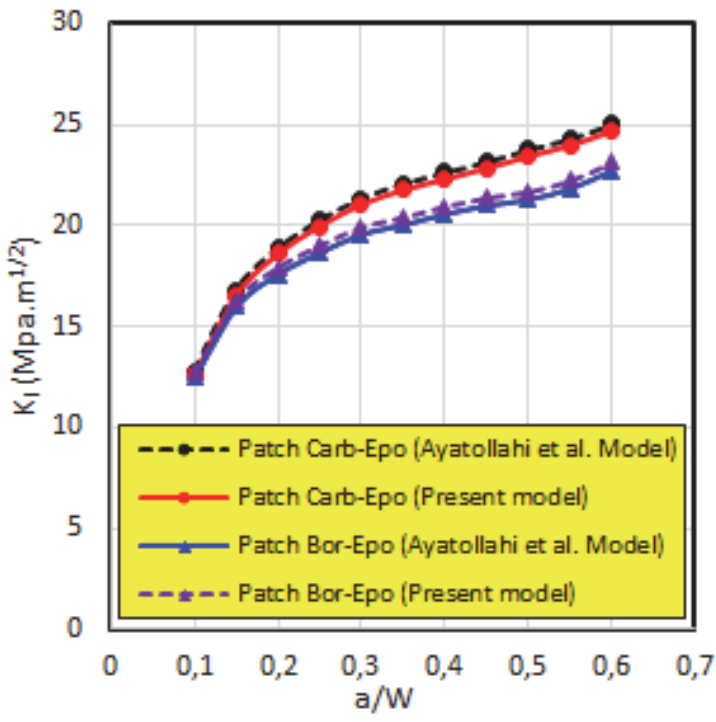

(b)

Figure 3: Variation of $\mathrm{K}_{\mathrm{I}}$ versus the crack length for (a) unpatched and (b) patched centre cracked specimen.

\section{RESULTS AND DisCUSSION}

\section{Distribution of von Mises stresses in the plates}

$\mathrm{F}$ igs. 4 and 5 respectively illustrate the distribution of von Mises stresses under different loadings using rectangular patches in boron/epoxy and carbon/epoxy in the case of a corroded plate without crack and a corroded and cracked plate. It can be noticed that in both cases the stresses increase with the increase of the applied load. A slight difference was found between the values obtained using boron/epoxy and carbon/epoxy patches.

For a loading less than $250 \mathrm{MPa}$, we noted a weak distribution of stresses at the level of the corroded surface in the case of an uncracked plate (Fig. 4.a-d). Exceeding a loading of $250 \mathrm{MPa}$, the effect of the patch becomes negligible and an almost homogeneous stresses distribution has been noted (Fig. 4.e-f).

In the case of a corroded and cracked plate (Fig. 5), it can be seen that there is more stress concentration at the right crack tip containing the corroded area compared to the crack tip area left. A non-homogeneous distribution of stresses is noted for the three loading cases under the effect of the crack and the corroded area for both patches. In addition, it can be observed that the maximum stresses obtained in the case of cracked and corroded plates are lower than those of the corroded plates without crack. This can be attributed to the presence of crack, which can play the role of stress deconcentration and reduction of the maximum stress value in the plate. 


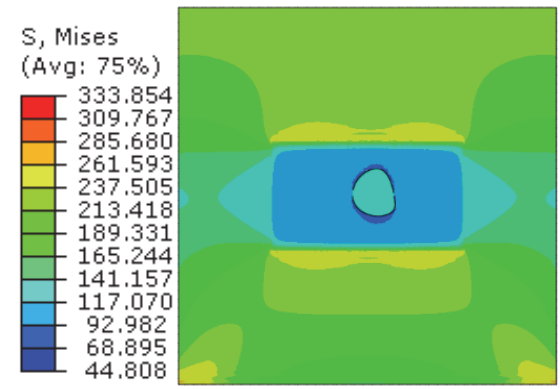

(a) Boron/epoxy patch with $\sigma=220 \mathrm{MPa}$

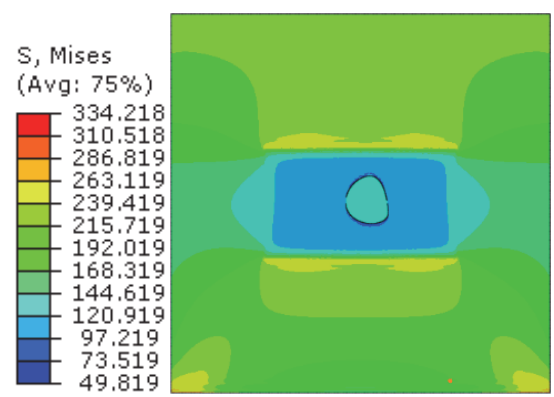

(b) Carbon/epoxy patch with $\sigma=220 \mathrm{MPa}$

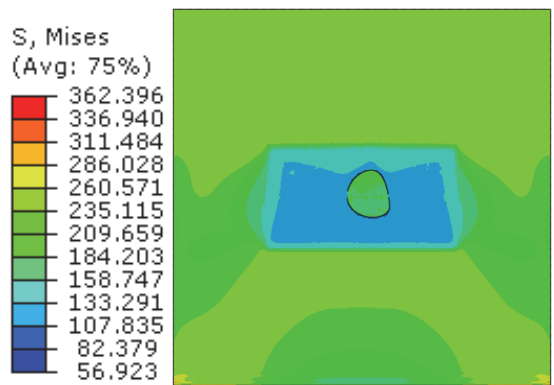

(c) Boron/epoxy patch with $\sigma=250 \mathrm{MPa}$

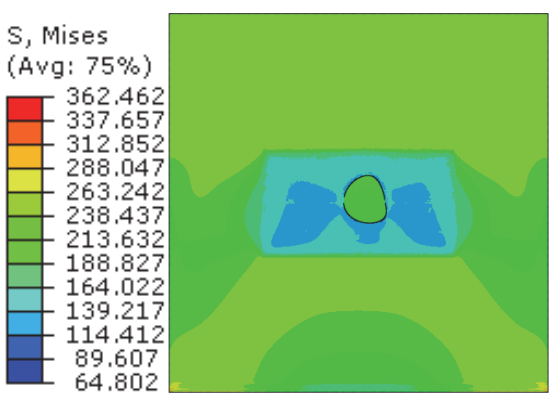

(d) Carbon/epoxy patch with $\sigma=250 \mathrm{MPa}$

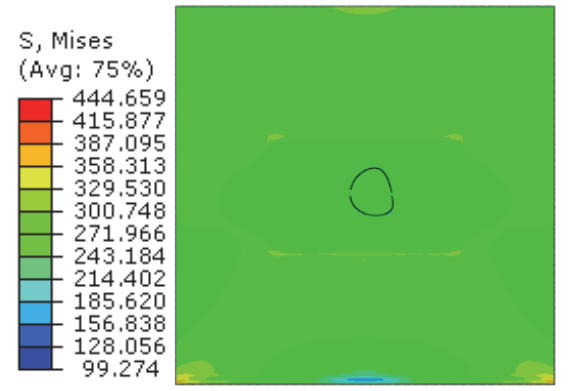

(e) Boron/epoxy patch with $\sigma=300 \mathrm{MPa}$

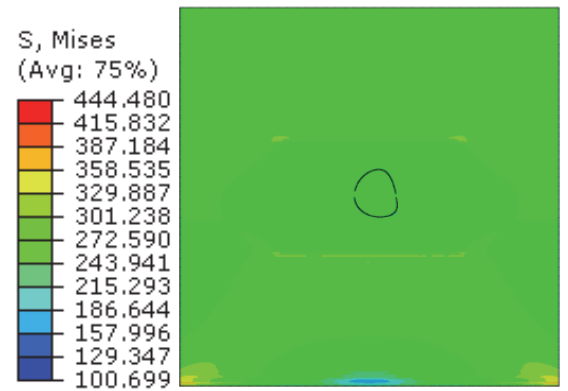

(f) Carbon/epoxy patch with $\sigma=300 \mathrm{MPa}$

Figure 4: Von Mises stresses distribution in the case of a corroded plate without crack under different loadings using rectangular boron/epoxy and carbon/epoxy patches.

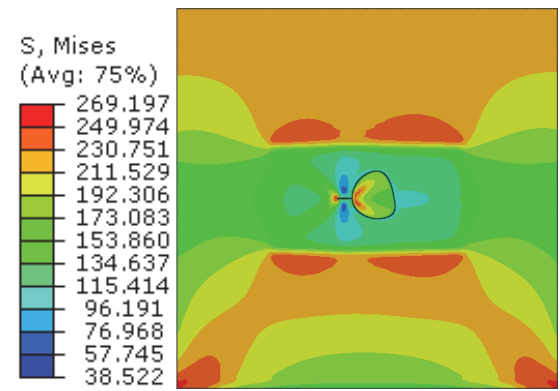

(a) Boron/epoxy patch with $\sigma=220 \mathrm{MPa}$

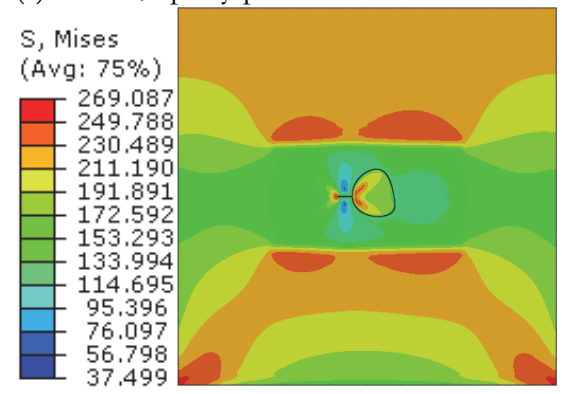

(b) Carbon/epoxy patch with $\sigma=220 \mathrm{MPa}$

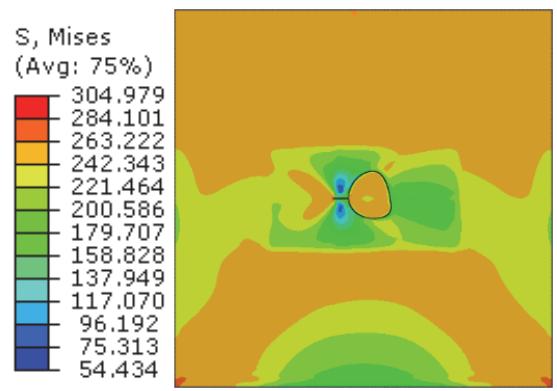

(c) Boron/epoxy patch with $\sigma=250 \mathrm{MPa}$

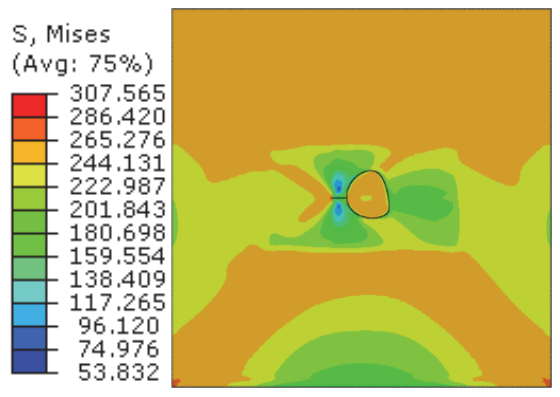

(d) Carbon/epoxy patch with $\sigma=250 \mathrm{MPa}$

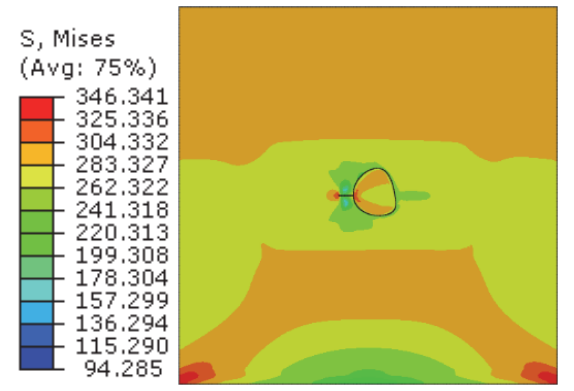

(e) Boron/epoxy patch with $\sigma=300 \mathrm{MPa}$

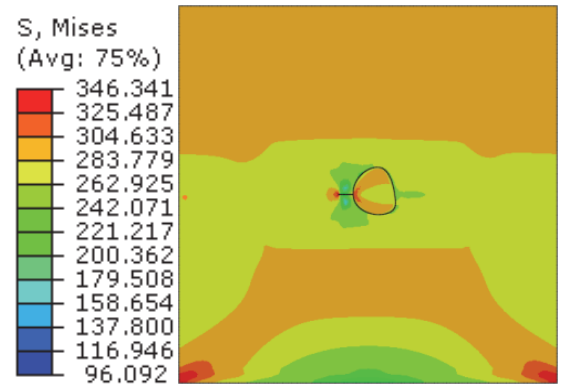

(f) Carbon/epoxy patch with $\sigma=300 \mathrm{MPa}$

Figure 5: Von Mises stresses distribution in the case of a corroded and cracked plate under different loadings using rectangular boron/epoxy and carbon/epoxy patches. 


\section{Distribution of von Mises stresses in the patches}

Figs. 6 and 7 show the von Mises stresses distributions in the boron/epoxy and carbon/epoxy patches for corroded plate without crack and corroded-cracked plate under different loadings. For both cases, it can be noticed that the stresses increase as the applied load increases. The stress concentration is localized on the edges of the patches for the corroded and uncracked plate (Fig. 6), whereas for the corroded-cracked plate (Fig. 7), we found more stress concentration at the vicinity of the corroded crack tip.

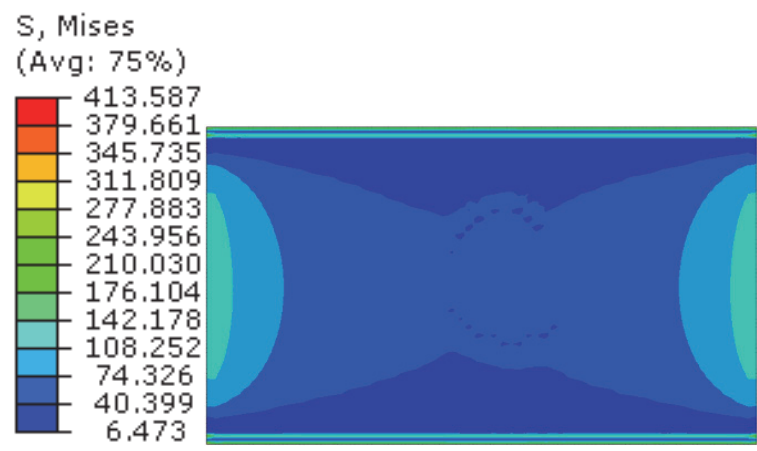

(a) Boron/epoxy patch with $\sigma=220 \mathrm{MPa}$

\section{S, Mises}

(Avg: $75 \%$ )

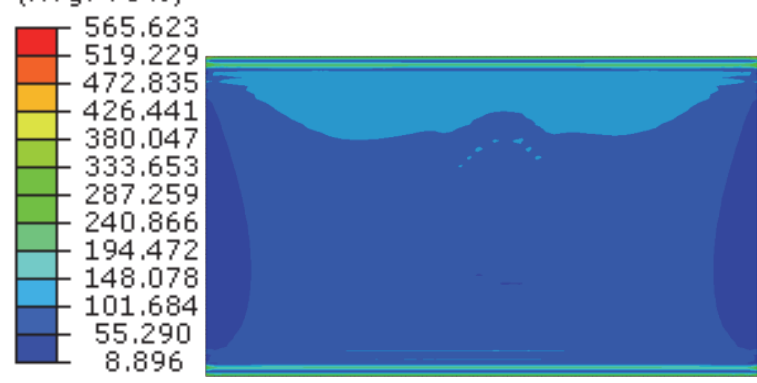

(c) Boron/epoxy patch with $\sigma=250 \mathrm{MPa}$

$$
\text { S, Mises }
$$

(Avg: 75\%)

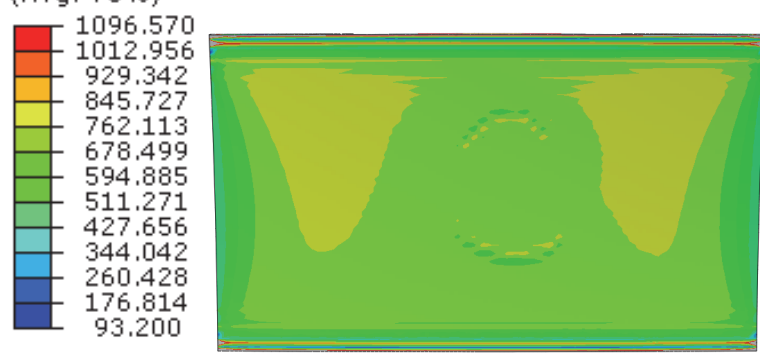

(e) Boron/epoxy patch with $\sigma=300 \mathrm{MPa}$

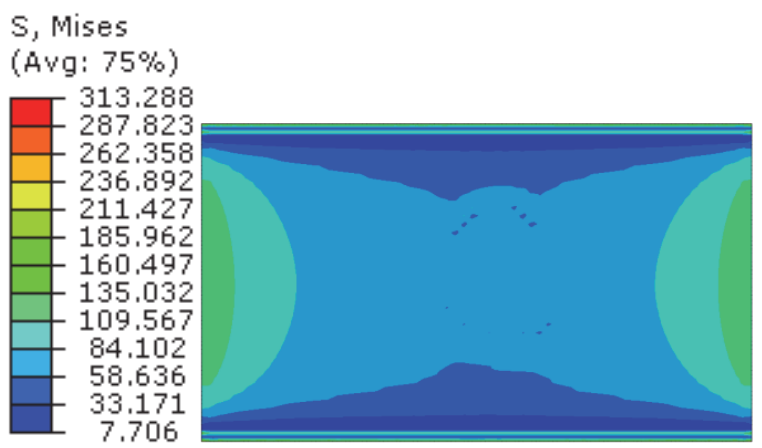

(b) Carbon/epoxy patch with $\sigma=220 \mathrm{MPa}$

S, Mises

(Avg: 75\%)

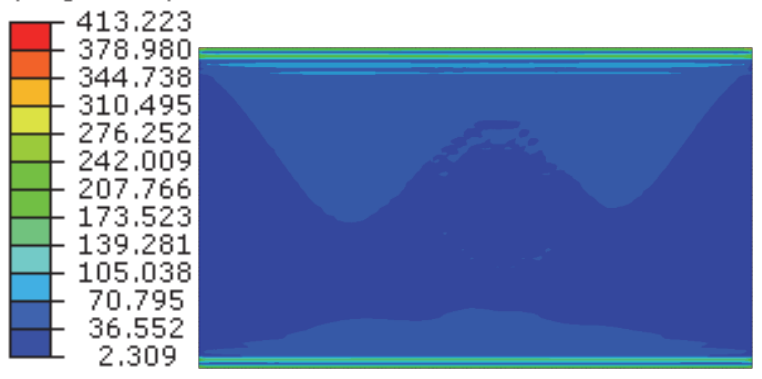

(d) Carbon/epoxy patch with $\sigma=250 \mathrm{MPa}$

$S$, Mises

(Avg: $75 \%$ )

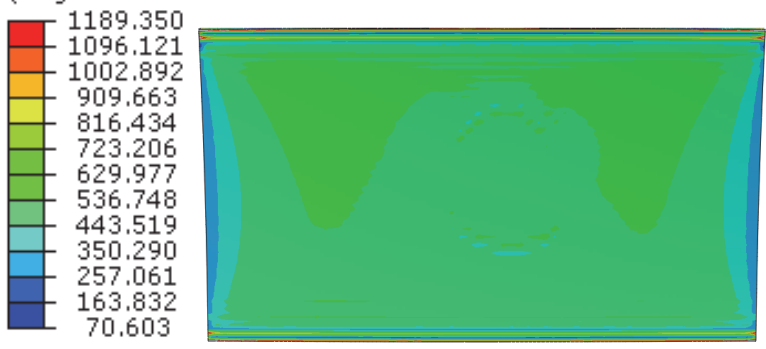

(f) Carbon/epoxy patch with $\sigma=300 \mathrm{MPa}$

Figure 6: Von Mises stresses distribution in the patches made in boron/epoxy and carbon/epoxy in the case of corroded and uncracked plate under different loadings. 


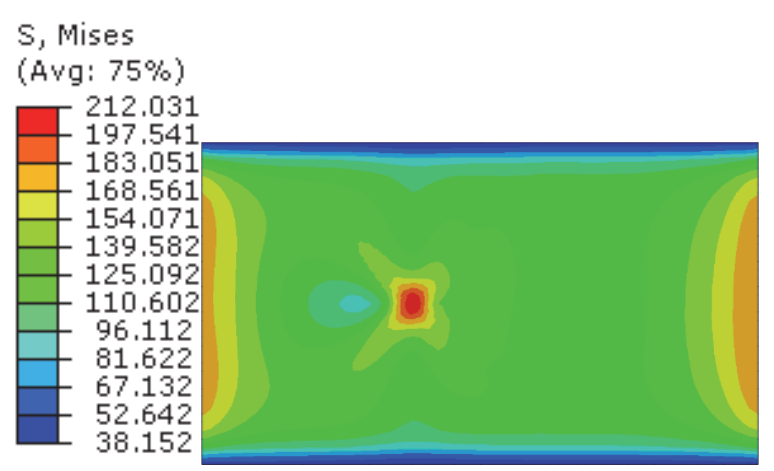

(a) Boron/epoxy patch with $\sigma=220 \mathrm{MPa}$

$$
\text { S, Mises }
$$

(Avg: $75 \%$ )

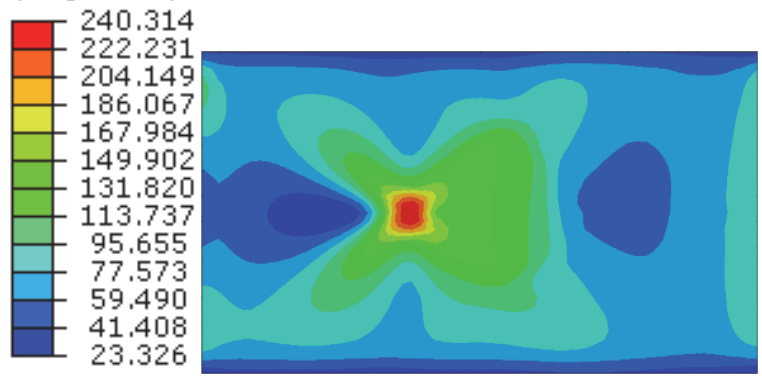

(c) Boron/epoxy patch with $\sigma=250 \mathrm{MPa}$

$$
\text { S, Mises }
$$

(Avg: 75\%)

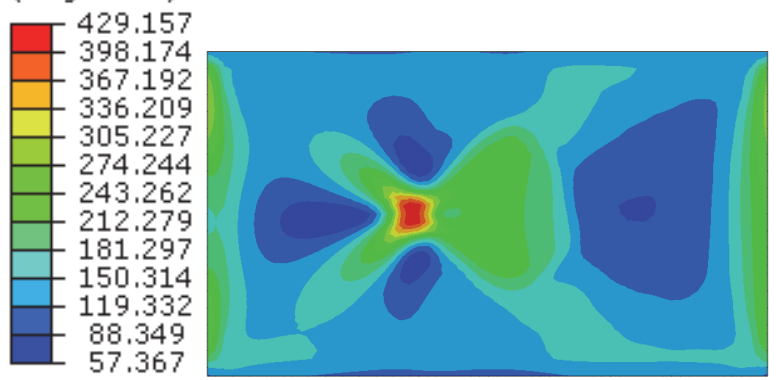

(e) Boron/epoxy patch with $\sigma=300 \mathrm{MPa}$

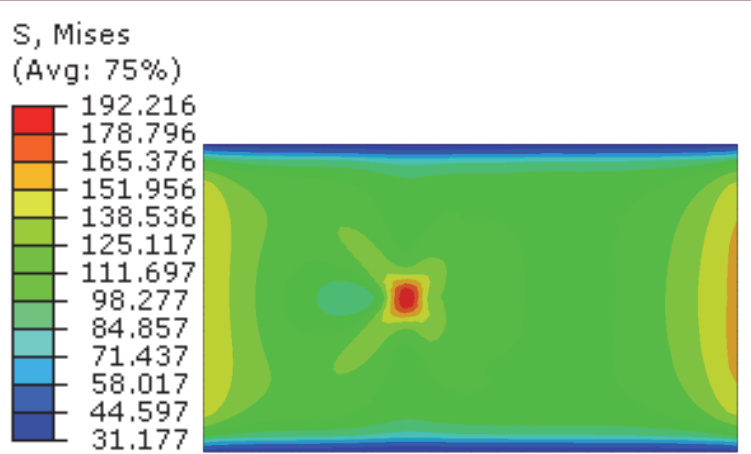

(b) Carbon/epoxy patch with $\sigma=220 \mathrm{MPa}$

\section{S, Mises}

(Avg: $75 \%$ )

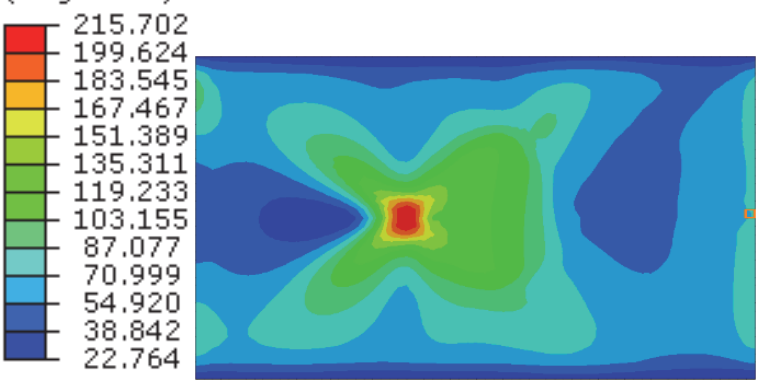

(d) Carbon/epoxy patch with $\sigma=250 \mathrm{MPa}$

S, Mises

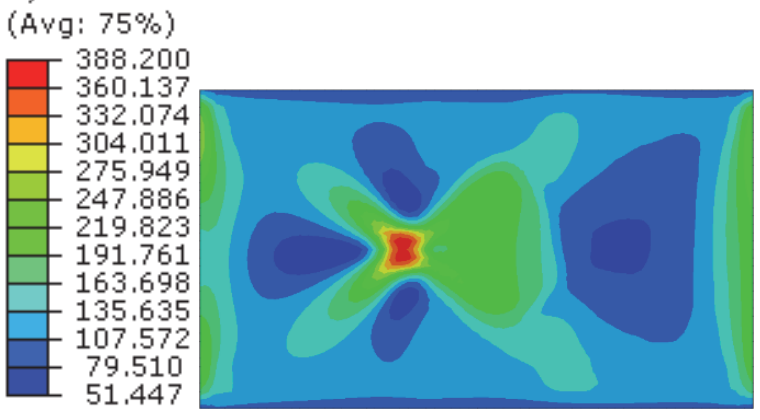

(f) Carbon/epoxy patch with $\sigma=300 \mathrm{MPa}$

Figure 7: Von Mises stresses distribution in patches made with boron/epoxy and carbon/epoxy in the case of corroded and cracked plate under different loadings.

\section{EVOLUTIONS OF THE DAMAGED ZONE}

\section{Case of the corroded and uncracked plate}

7 ig. 8 illustrates the evolutions of the damaged areas (gray surfaces) of the adhesive used for the repair of the 1 corroded plate with carbon/epoxy and boron/epoxy patches under different loadings $\sigma=220,250,300$ and 350 $1 \mathrm{MPa}$. It can be seen that the damaged area increases with the increase of the load for both patches, until it reaches a critical value $\left(\mathrm{D}_{\mathrm{r}}=0.2474\right)$ for the high loads (especially when $\left.\sigma=350 \mathrm{MPa}\right)$, where the adhesive loses its rigidity and the adherence between the composite and the metal becomes very weakened as demonstrated by several authors [9,24,25]. In this case, we can note that corrosion plays an important role on the repair quality, however when the applied loads are below $300 \mathrm{MPa}$, a good repair performance has been noticed.

Fig. 9 presents the evolution of damage ratio as a function of the applied load in the case of corroded plate without crack. We can note that as long as the load is less than $\sigma=320 \mathrm{MPa}$ both types of patches maintain their integrity and the adhesive rigidity is better. That can be explain by the value of $D_{r}$ which does not exceed its critical estimated value 
$\mathrm{Dr}=0.2474$. However, the adhesive of boron/epoxy patch presents a higher integrity than that of carbon/epoxy patch as it can be seen on the blue curve (Fig. 9), where the values of $\mathrm{D}_{\mathrm{r}}$ are more reduced.

When the applied load exceeds $320 \mathrm{MPa}$, it can be observed that the repair by carbon/epoxy patch is not effective, because the adhesive loses its rigidity and the damage ratio exceeds its critical value. On the other hand, it seems that the adhesive of boron/epoxy patch retains its rigidity up to a value close to $350 \mathrm{MPa}$.

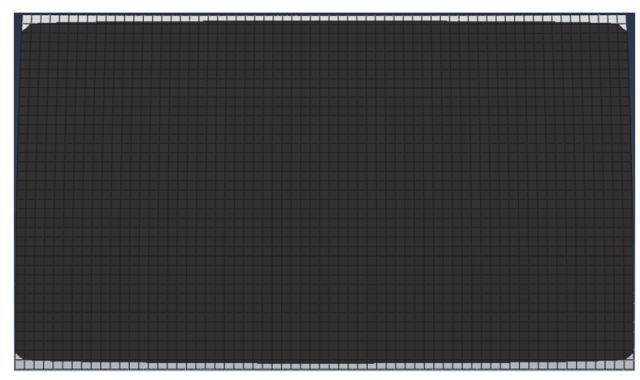

(a) Boron/epoxy patch with $\sigma=220 \mathrm{MPa}$

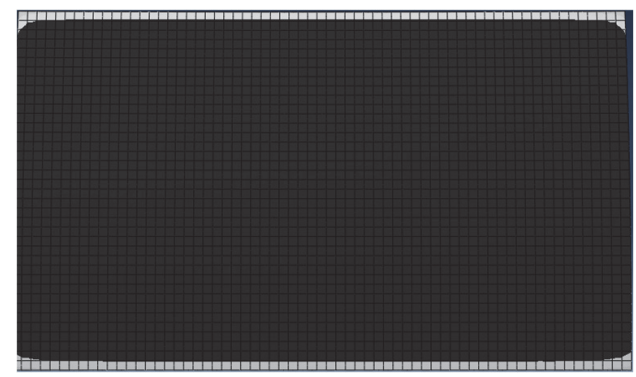

(c) Boron/epoxy patch with $\sigma=250 \mathrm{MPa}$

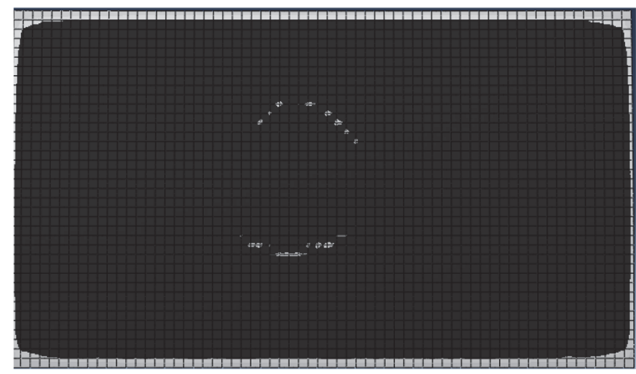

(e) Boron/epoxy patch with $\sigma=300 \mathrm{MPa}$

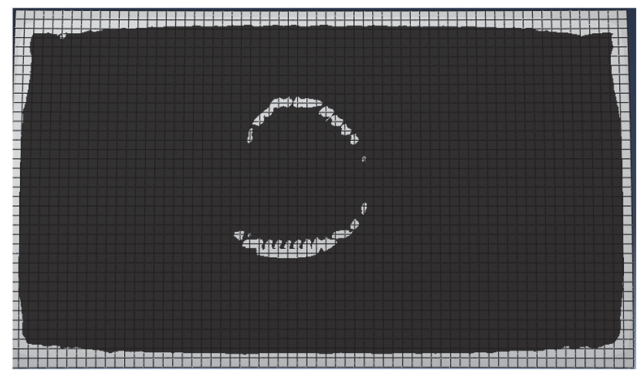

(g) Boron/epoxy patch with $\sigma=350 \mathrm{MPa}$

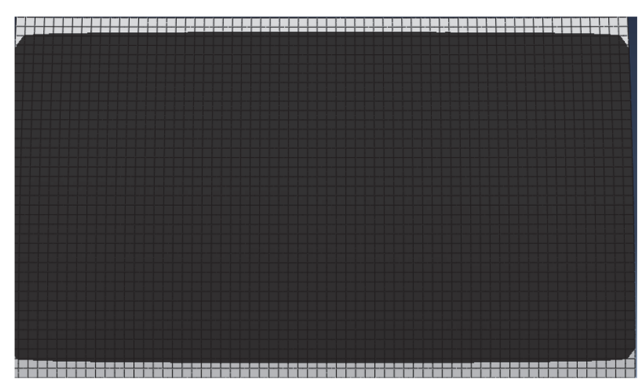

(b) Carbon/epoxy patch with $\sigma=220 \mathrm{MPa}$

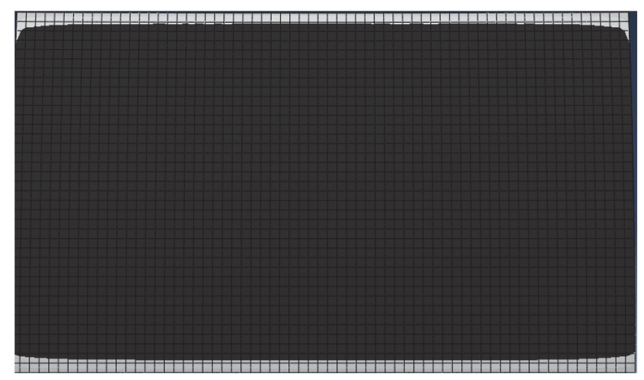

(d) Carbon/epoxy patch with $\sigma=250 \mathrm{MPa}$

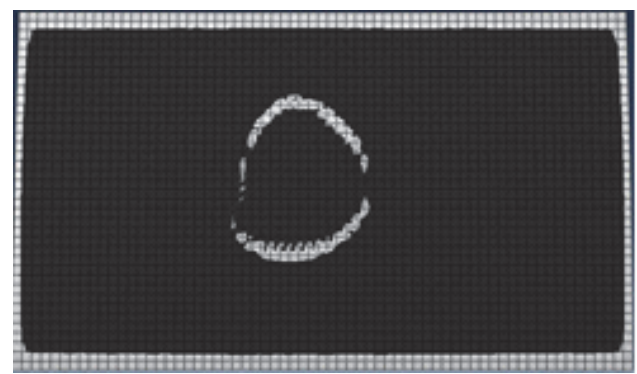

(f) Carbon/epoxy patch with $\sigma=300 \mathrm{MPa}$

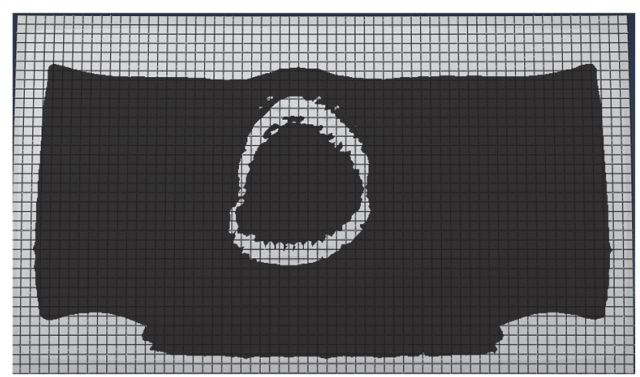

(h) Carbon/epoxy patch with $\sigma=350 \mathrm{MPa}$

Figure 8: Evolution of the damaged area of the adhesive used to repair the corroded and uncracked plate by boron/epoxy and carbon/epoxy patches under different loadings. 


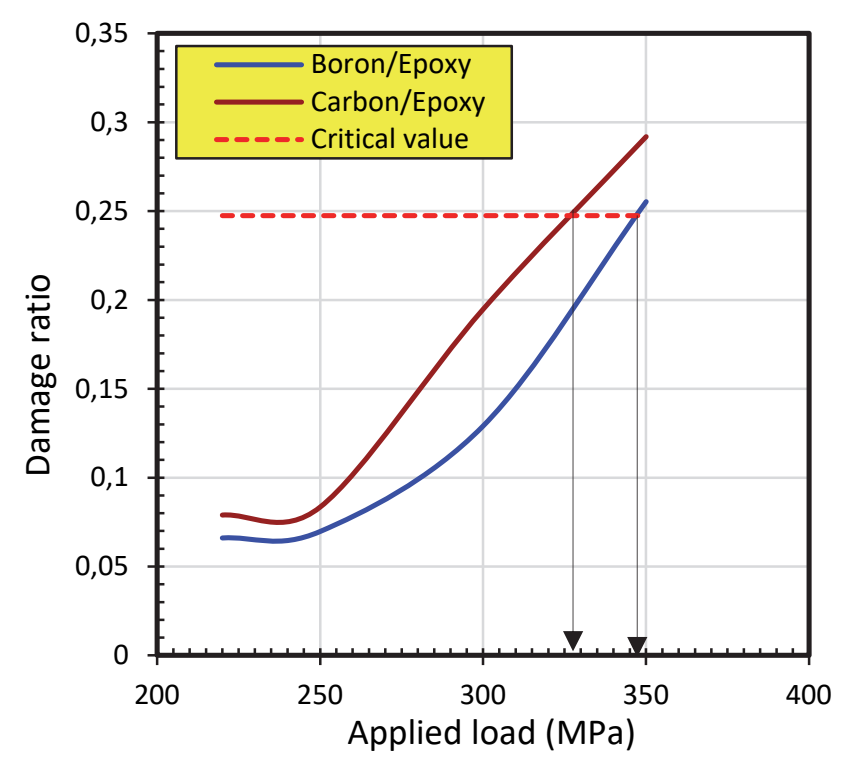

Figure 9: Evolution of damage ratio versus the applied load in the case of a corroded plate without crack.

\section{Case of the corroded and cracked plate}

Fig. 10 shows the evolutions of the damaged area of the adhesive used to repair the cracked and corroded plate by boron/epoxy and carbon/epoxy patches under different loadings. It can be seen that for the load $\sigma=220 \mathrm{MPa}$, the plate repaired by boron/epoxy patch has less damage than that made of carbon/epoxy. The damage of repair adhesive FM73 is localized at the upper and lower edges for the plate repaired by boron/epoxy patch, while for the plate repaired by carbon/epoxy patch, the adhesive damage is localized at the edges and at the vicinity of the crack tip (corroded area).

For the case of an applied load $\sigma=250 \mathrm{MPa}$, the damage of the adhesive is located at the vicinity of the corroded and cracked zone for both types of patches with less risk of disintegration.

When the applied load is $\sigma=300 \mathrm{MPa}$, it is clearly seen that the adhesive of boron/epoxy patch has less damage than that of carbon/epoxy patch, the latter being much damaged at the level of the corroded and cracked zone. This can be explained by the presence of a crack which can propagate more and more as the load increases.

For the applied load $\sigma=350 \mathrm{MPa}$, the adhesive damage is very significant and represents a risk of disintegration between the patch and the repaired plate. Indeed, in the case of high loads, repair by both types of patches does not have an effective impact and especially in the presence of crack with a corrosion defect on the repair plate.

The repair adhesive made with boron/epoxy patch has less damage compared to that of carbon/epoxy patch, in particular for very high loads. Therefore, it is recommended to use a boron/epoxy patch since it is relatively safer in the presence of an aggressive medium, such as seawater with very high degree of corrosion.

Figure 11 shows the evolution of damage ratio as a function of the applied load in the case of a corroded and cracked plate. It can be seen that the damage ratio in the adhesive of the carbon/epoxy patch is always higher than that of boron/epoxy, except in the case of an applied load of $245 \mathrm{MPa}$ where both patches present the same damage ratio.

In addition, it can be noted that the maximum loads for which the damage ratio reaches its critical value are about 292 $\mathrm{MPa}$ for the carbon/epoxy patch and $332 \mathrm{MPa}$ for the boron/epoxy patch.

\section{Evolution of J-integral}

Fig. 12 presents a comparison of the J-integral evolutions as a function of the applied load for the two cracked and corroded plates repaired by both patches with that of the cracked and corroded plate not repaired. According to this figure, it can be observed that for loads less or equal to $300 \mathrm{MPa}$, both patches give almost the same results for the repair of the corroded and cracked aluminum alloy A5083. However, for loads greater than $300 \mathrm{MPa}$ the patch made in boron/epoxy gives a better repair in terms of efficiency compared to that of carbon/epoxy. 


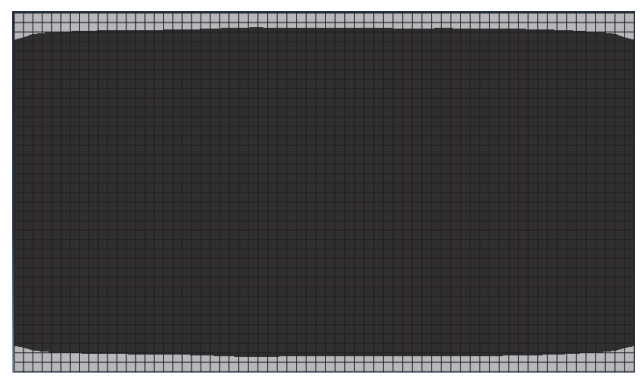

(a) Boron/epoxy patch with $\sigma=220 \mathrm{MPa}$

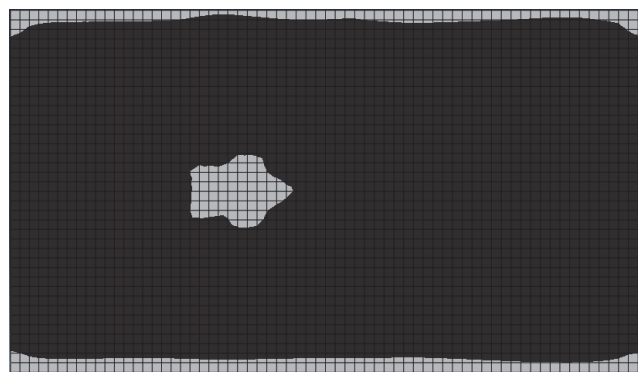

(c) Boron/epoxy patch with $\sigma=250 \mathrm{MPa}$

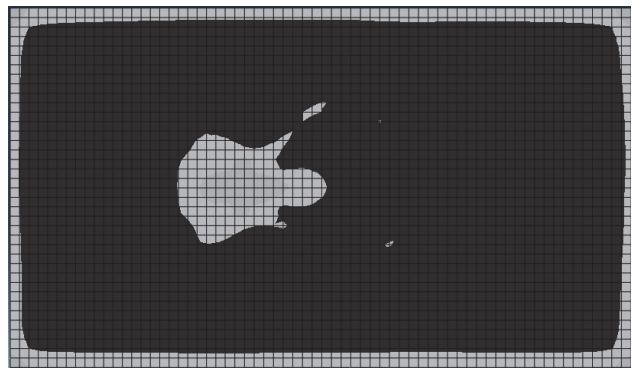

(e Boron/epoxy patch with $\sigma=300 \mathrm{MPa}$

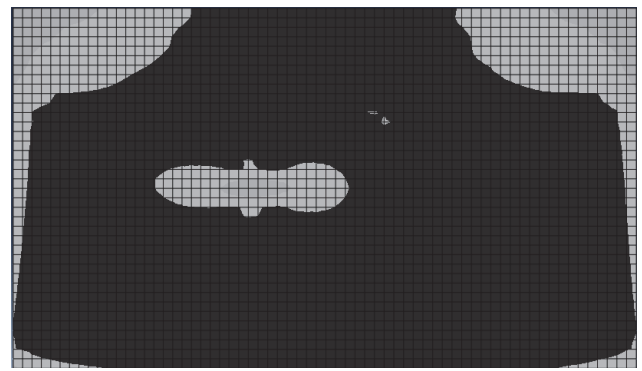

(g) Boron/epoxy patch with $\sigma=350 \mathrm{MPa}$

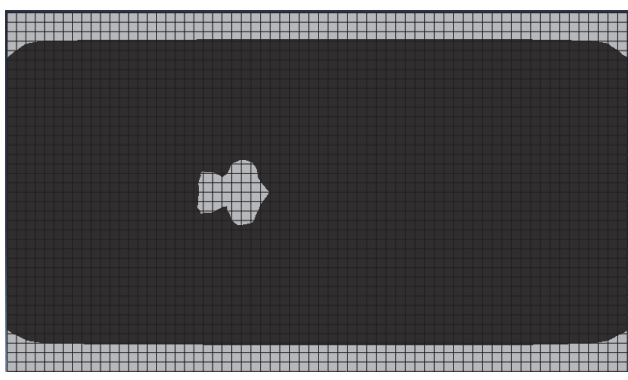

(b) Patch in carbon/epoxy with $\sigma=220 \mathrm{MPa}$

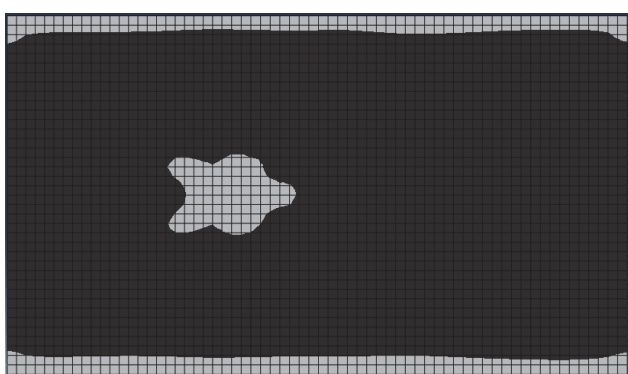

(d) Patch in carbon/epoxy with $\sigma=250 \mathrm{MPa}$

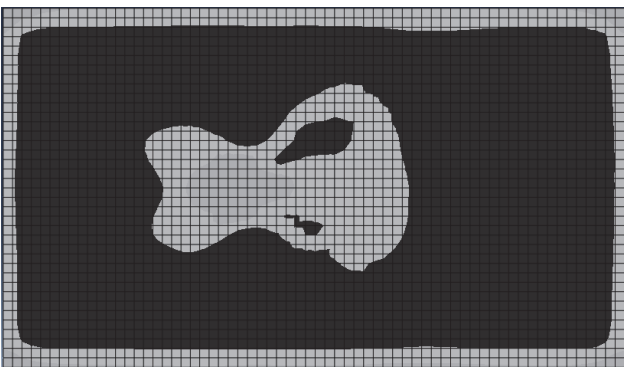

(f) Patch in carbon/epoxy with $\sigma=300 \mathrm{MPa}$

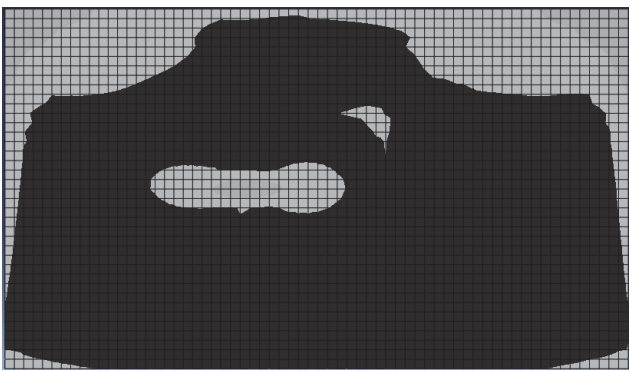

(h) Patch in carbon/epoxy with $\sigma=350 \mathrm{MPa}$

Figure 10: Evolution of the damaged area of the adhesive used for the repair of the cracked and corroded plate by boron/epoxy and carbon/epoxy patches under different loadings.

In addition, it can be seen that the effectiveness of patch repair increases with the increase of the applied load. Indeed, the difference between the J-integral values for the plate repaired by boron/epoxy patch (the best) and not repaired varies between $40.75 \%$ and $215.90 \%$ for loads varying between 220 and $400 \mathrm{Mpa}$ respectively. 


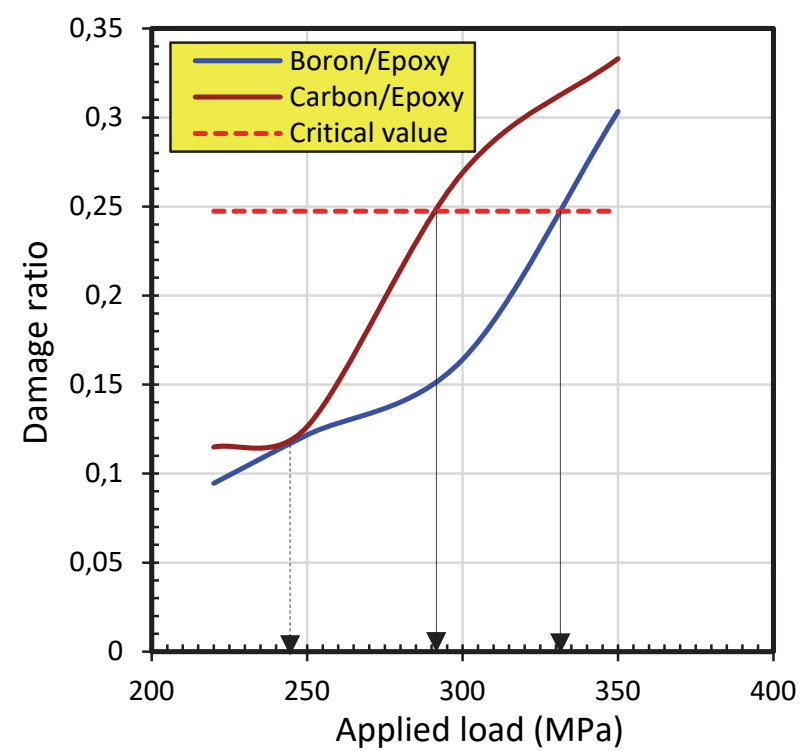

Figure 11: Evolution of damage ratio versus the applied loads in the case of a corroded and cracked plate.

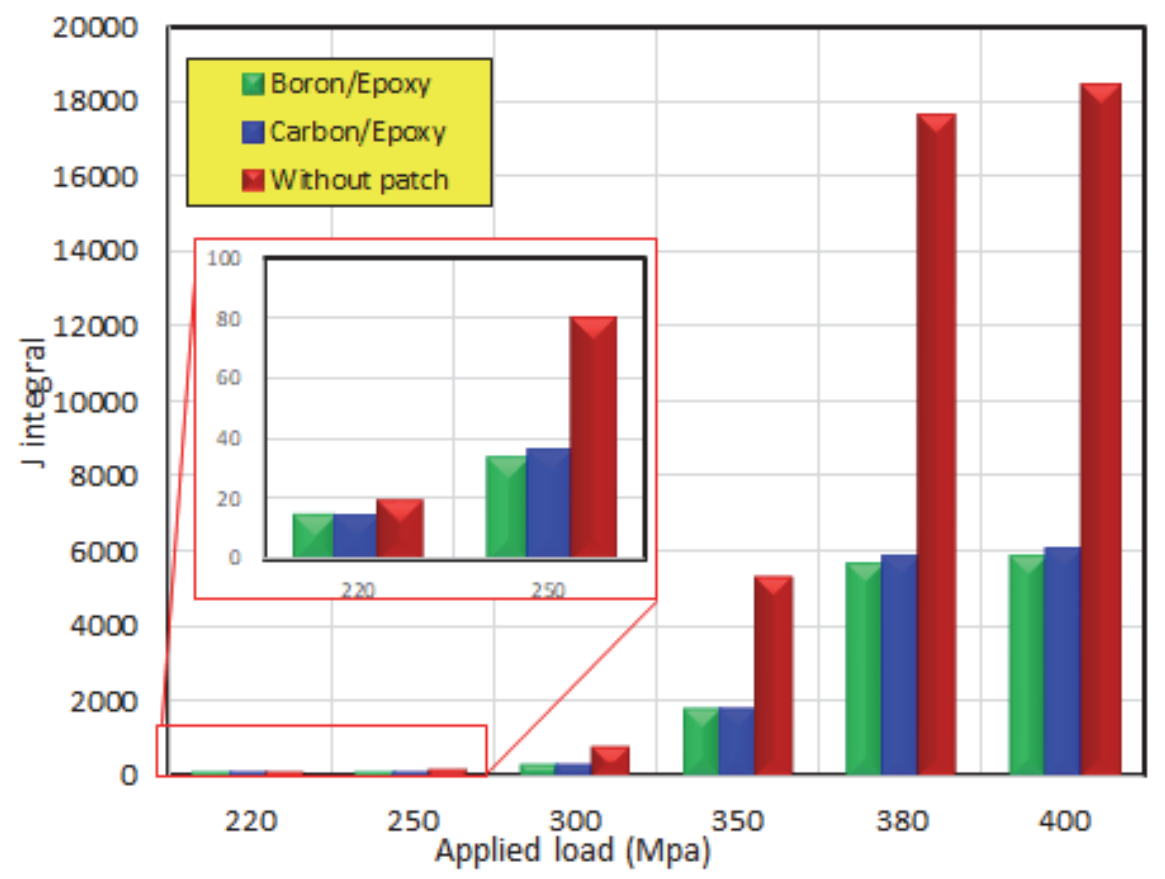

Figure 12: Evolution of the J-integral as a function of the applied load for the cracked and corroded plate repaired by both patches compared to that of the cracked and corroded plate not repaired.

\section{CONCLUSION}

A

luminum alloys, especially the A5083 H11 has a good resistance to corrosion pitting, in the marine environment, making it the best choice for marine industry manufacturing, over time. This aluminum alloy tends to lose these mechanical and chemical characteristics in contact with an aggressive medium such as seawater which is qualified as a saline and saturated medium and which will cause or accelerate the oxidation reaction. The major problem in marine 
industries is corrosion, which plays an important role in the propagation of micro cracks under the effect of stress corrosion or metallurgical defect such as endogenous or exogenous inclusions during the development of this latter.

The different forms and mechanisms of corrosion presented by a previous work and described in this paper have allowed us to understand the phenomenon in order to act better in repairing the corroded and cracked zone.

Based on the results obtained in this study of the corrosion effect on the repair performance of the cracked plates with composite patches, the following conclusions can be drawn:

$\checkmark$ Increasing the applied load implies an increase in the damage ratio $D_{r}$ of the adhesive.

$\checkmark$ The repair with both types of patches (boron/epoxy and carbon/epoxy) gives an acceptable repair performance for cases of loads lower than $300 \mathrm{MPa}$ without risk of adhesive disband.

$\checkmark$ For severe loads and higher than 300MPa and the case of the repair of corroded and cracked 5083 aluminum alloy structures, it is recommended to use a boron/epoxy patch since it provides a better performance and, therefore, longer service life compared to a carbon/epoxy patch.

\section{ACKNOWLEDGEMENTS}

7 his research was supported by the General Directorate of Scientific Research and Technological Development (DGRSDT: Direction Générale de la Recherche Scientifique et du Développement Technologique) of Algeria. The authors gratefully acknowledge the scientific support of LABAB Laboratory (ENP Oran, Algeria), LMPM Laboratory (Sidi Bel Abbes University, Algeria) and Lille Mechanics Unit (France).

\section{REFERENCES}

[1] Sielski, R.A., (2008). Research needs in aluminum structure, Ships Offshore Struct., 3(1), pp. 57-65. DOI: $10.1080 / 17445300701797111$.

[2] Bailey, J.C., Porter, F.C., Pearson, A.W., and Jarman, R.A., (1994). Aluminium and Aluminium alloys, in Corrosion (Third Edition), Butterworth-Heinemann: Oxford. p. 4:3-3:37, DOI: 10.1016/j.matpr.2018.05.143.

[3] Reinhart, F.M., (1976). Corrosion of metals and alloys in the deep ocean, Technical report (Naval Construction Battalion Center (Port Hueneme, Calif.). Civil Engineering Laboratory); R834. DOI: 10.5962/bhl.title.47711

[4] Ding, Y., Lv, Y., Zhao, B., Han, Y., Wang, L., Lu, W., (2018). Response relationship between loading condition and corrosion fatigue behavior of nickel-aluminum bronze alloy and its crack tip damage mechanism, Mater Charact., (144) pp. 356-367. DOI: 10.1016/j.matchar.2018.07.033.

[5] Campbell, F.C., (2008). Elements of Metallurgy and Engineering Alloys, ASM International. DOI: 10.31399 /asm.tb.emea.9781627082518

[6] Salem, M., Bachir Bouiadjra, B.B., Mechab, B., and Kaddouri, K., (2015). Elastic-plastic analysis of the J integral for repaired cracks in plates, Struct. Eng. Mech., 4(2), pp. 87-96. DOI: 10.12989/amr.2015.4.2.087.

[7] Katnam, K.B., Da Silva, L.F.M., and Young, T.M., (2013). Bonded repair of composite aircraft structures: a review of scientific challenges and opportunities. Prog. Aerosp. Sci. 61, pp. 26-42. DOI: 10.1016/j.paerosci.2013.03.003.

[8] Sadek, K., Aour, B., Bachir Bouiadjra, B., Fari Bouanani, M., and Khelil, F., (2018). Analysis of Crack Propagation by Bonded Composite for Different Patch Shapes Repairs in Marine Structures: A Numerical Analysis, Int. J. Eng. Res. Afr., 35, pp. 175-184. DOI: 10.4028/www.scientific.net/JERA.35.175

[9] Sadek, K., Bennouna, M.S., Aour, B., Bachir Bouiadjra, B., Benaissa, A., and Fari Bouanani, M., (2019). Numerical Investigation of the Adhesive Damage Used for the Repair of A5083 H11 Aluminum Structure by composites patches, Int. J. Eng. Res. Afr., 44, pp. 22-31. DOI: 10.4028/www.scientific.net/JERA.44.22.

[10] Berrahou, M., Mokadem, S., Mechab, B., and Bachir Bouiadjra, B., (2017). Effect of the corrosion of plate with double cracks in bonded composite repair, Struct. Eng. Mech., 64(3), pp. 323-328. DOI: DOI: 10.12989/sem.2017.64.3.323.

[11] Leski, A., (2007). Implementation of the virtual crack closure technique in engineering FE calculations, Finite Elem. Anal. Des., (43), pp. 261-268. DOI: 10.1016/j.finel.2006.10.004.

[12] Rybicki, E.F., Kanninen, M.F., (1977). A finite element calculation of stress intensity factors by a modified crack closure integral, Eng. Fract. Mech., 9(4), pp. 931-938. DOI: 10.1016/0013-7944(77)90013-3.

[13] Frigon, N.L., Mathews, D., (1996). Practical guide to experimental design, $1^{\text {st }}$ Edition, Wiley, NewYork. ISBN: 978-0471-13919-5 November 1996360 Pages. 
[14] Eriksson, L., Johansson, E., Kettaneh-Wold, N., Wikström, C., and Wold, S., (2000). Design of experiments: principles and applications, third Edition, Umetrics AB, DOI: 10.1002/cem.686.

[15] Ait Yala, A., and Megueni, A., (2009). Optimisation of composite patches repairs with the design of experiments method, Mater. Design, 30(1), pp. 200-205. DOI: 10.1016/j.matdes.2008.04.049.

[16] Fekih, S.M., Albedah, A., Benyahia, F., Belhouari, M., Bachir Bouiadjra, B., Miloudi, A., (2012). Optimisation of the sizes of bonded composite repair in aircraft structures, Mater. Design, (41), 171-176. DOI: 10.1016/j.matdes.2012.04.025.

[17] Sheppard, A., Kelly, D., and Tong, L., (1998). A damage zone model for the failure analysis of adhesively bonded joints. Int J Adhesion Adhesives, 18(6), pp. 385-400, DOI: 10.1016/S0143-7496(98)00024-4.

[18] Ban, C.S., Lee, Y.H., Choi, J.H., Kweon, J.H., (2008). Strength prediction of adhesive joints using the modified damage zone theory, Compos. Struct., 86, pp. 96-100. DOI: 10.1016/j.compstruct.2008.03.016.

[19] Berrahou, M., Mokadem, S., Mechab, B., Bachir Bouiadjrab, B., (2017). Effect of the corrosion of plate with double cracks in bonded composite repair, Struct. Eng. Mech., 64(3), pp. 323-328.

[20] Mhamdia, R., Bachir Bouadjra, B., Serier, B., Ouddad, W., Feaugas, X., Touzain, S., (2011). Stress intensity factor for repaired crack with bonded composite patch under thermo-mechanical loading, J. Reinf. Plast. Comp., 30(5), pp. 416424. DOI: $10.1177 / 0731684410397899$.

[21] Hibbit Karlsson \& Sorensen, (2015). ABAQUS Standard/User's Manual, Version 6.14., Inc., Pawtucket, RI, USA.

[22] Ayatollahi, M.R., Hashemi, R., (2007). Computation of stress intensity factors ( $\left.\mathrm{K}_{\mathrm{I}}, \mathrm{KII}\right)$ and T-stress for cracks reinforced by composite patching. Compos. Struct., 78, pp. 602-609. DOI: 10.1016/j.compstruct.2005.11.024.

[23] Ouinas, D., Bachir Bouiadjra, B., Himouri, S., Benderdouche, N., (2012). Progressive edge cracked aluminium plate repaired with adhesively bonded composite patch under full width disbond. Compos. B Eng., 43, pp. 805-811. DOI:10.1016/j.compositesb.2011.08.022.

[24] Grabovac, I., Bartholomeusz, R.A., and Baker, A.A., (1993). Composite reinforcement of a ship superstructure-project overview, Composites, 24(6) pp. 501-510. DOI: 10.1016/0010-4361(93)90020-9.

[25] Schubbe, J.J., Bolstad, S.H., Reyes, S., (2016). Fatigue crack growth behavior of aerospace and ship grade aluminum repaired with composite patches in a corrosive environment, Compos. Struct., 144, pp. 44-56.

DOI: $10.1016 /$ j.compstruct.2016.01.107. 